\title{
Concepts of trust in patients with serious illness focused on physician interpersonal and technical competence
}

Mechanic D, Meyer S. Concepts of trust among patients with serious illness. Soc Sci Med 2000 Sep.51:657-68.

\section{QUESTION: How do patients with serious medical conditions conceptualise and assess trust in their physicians?}

Design

Exploratory descriptive study.

\section{Setting}

New Jersey, USA.

\section{Patients}

30 women (mean age 56 y) with breast cancer, 30 patients (mean age 48 y, 83\% women) with Lyme disease, and 30 patients (mean age $43 \mathrm{y}, 53 \%$ men) with a serious psychiatric illness.

\section{Methods}

In semi-structured interviews, patients were asked about various aspects of their interactions with their physicians, medical institutions, and healthcare plans. The interview schedule was based on a conceptualisation of 5 dimensions of trust that were identified from a literature review (competence, fiduciary responsibility and agency, control, confidentiality, and disclosure). Interviews were audiotaped and transcribed; individual phrases were coded using the above conceptualisation.

\section{Main findings}

Patient responses to the question "what does trust mean to you?" ranged across the dimensions of competence, agency, and confidentiality; control and disclosure were seldom mentioned.

The dimension of competence included both interpersonal and technical competence. Patients put most emphasis on the interpersonal competence of their physicians, which was predominantly described in terms of listening. Other descriptors included caring, concern, and compassion. Technical competence related to a physician's experience, thoroughness, and knowledge. Patients assessed technical competence based on their experiences and how they felt their illnesses were progressing under treatment. Individual patients had different levels of knowledge and resourcefulness in learning about their diseases, and therefore developed different expectations about the nature of technical competence, which were subsequently compared with their unfolding experiences. With regard to fiduciary responsibility and agency, most patients had difficulty accepting that their physician might need to weigh their needs against other interests. Trust in this context focused on commitment to the patient and patient advocacy. The dimension of control referred to the notion that within a managed care system, physicians might not be able to control their patients' pattern of care and treatment. Although patients with serious illness increasingly encounter the conflict between their physicians and their healthcare plans, for most patients the uncertainty about whether their physician could get them the treatment they need remained a hypothetical concern. In general, confidentiality was not an important issue in trust because most patients believed that their physicians maintained their confidences. Patients were not familiar with issues of physician disclosure of incentives and conflicts of interest, but when asked specifically, they expressed repugnance at the thought that their physician might base medical decisions on personal gain; most, however, did not feel it appropriate to ask their physicians to make such disclosures.

\section{Conclusions}

Patients with serious illnesses such as breast cancer, Lyme disease, and psychiatric illness viewed trust as an iterative process in which they tested their physicians against their own knowledge and expectations. Interpersonal competence focused on listening was a major dimension of trust; technical competence and agency were other important dimensions. Control, confidentiality, and disclosure were less common concerns.

\section{COMMENTARY}

The study by Mechanic and Meyer provides valuable evidence in revealing the dimensions of trust inherent in physician-patient relationships. Similar studies have shown the importance of technical and interpersonal competence. ${ }^{12}$ Previous research, however, has also highlighted patient control or autonomy-expressed as the building of partnerships, ${ }^{12}$ reciprocal trust, ${ }^{3}$ or patient decision making. ${ }^{4}$ This lack of emphasis on patient autonomy may be the result of using a sample that consisted wholly of patients with serious illness. These patients have been found to desire less autonomy in medical decision making. ${ }^{5}$ Patients in the previous studies were receiving various healthcare services including primary care, ${ }^{1}$ natural health care, ${ }^{2}$ and home care ${ }^{3}$ or were described as having a chronic illness ${ }^{4}$ and thus many might not have been seriously ill.

Several recommendations for nursing can be drawn from the findings. The centrality of interpersonal competence in building patient trust supports continued efforts to promote and sustain the interpersonal skills of nurses. The authors emphasise that some of these skills are teachable, such as listening and communicating clearly. The results of this and previous studies suggest that nurses should be sensitive to the degree of autonomy desired by patients, which may be dependent upon the seriousness of their illnesses.

\section{Elizabeth Peter, RN, PhD Assistant Professor, Faculty of Nursing Member, Joint Centre for Bioethics University of Toronto \\ Toronto, Ontario, Canada}

1 Thom DH, Campbell B. Patient-physician trust: an exploratory study. J Fam Pract 1997:44:169-76.

2 Semmes CE. Developing trust: patient-practitioner encounters in natural health care. $J$ Contemporary Ethnography 1991;19:450-70.

3 Thorne SE, Robinson CA. Reciprocal trust in health care relationships. J Adv Nurs 1988;13:782-9.

4 Trojan L, Yonge O. Developing trusting, caring relationships: home care nurses and elderly clients. J Adv Nur 1993;18:1903-10.

5 Schneider CE. The practice of autonomy: patients, doctors, and medical decisions. New York: Oxford University Press, 1998. 